\title{
Myocardial Blood Flow
}

National Cancer Institute

\section{Source}

National Cancer Institute. Myocardial Blood Flow. NCI Thesaurus. Code C94939.

Perfusion of blood through the myocardium. 